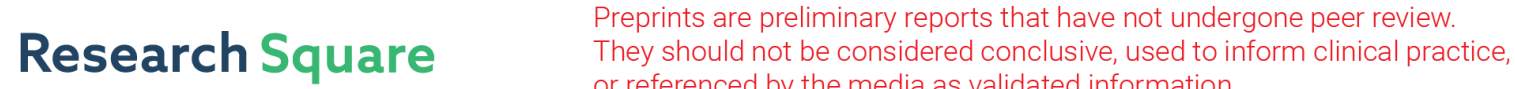 or referenced by the media as validated information. \\ Identification and functional analysis of bacteria in sclerotia of Cordyceps militaris
}

\section{Li Luo}

Guizhou University

Jia-Xi Zhou

Guizhou University

\section{Zhong-Shun Xu}

Guizhou University

\section{Ying-Ming Gao}

Guizhou University

Xiao Zou ( $\sim$ xzou@gzu.edu.cn )

Guizhou University

\section{Research Article}

Keywords: Cordyceps militaris, Microbial community, Co-culture, Functional analysis

Posted Date: May 12th, 2021

DOl: https://doi.org/10.21203/rs.3.rs-513248/v1

License: (c) (1) This work is licensed under a Creative Commons Attribution 4.0 International License. Read Full License

Version of Record: A version of this preprint was published at PeerJ on November 25th, 2021. See the published version at https://doi.org/10.7717/peerj.12511. 


\section{Abstract \\ Background}

Cordyceps militaris is a fungus that parasitizes insects. Compounds from C. militaris are valuable in medicine and functional food. There are many kinds of bacteria in the natural sclerotia of $C$. militaris. However, the community structure of microorganisms in samples from different places may be different, and the corresponding ecological functions require experimental verification.

\section{Results}

We used high-throughput sequencing technology to analyze bacterial 16S rRNA gene sequences in sclerotia of three samples of $C$. militaris from Liaoning Province, China. Pseudomonas, Pedobacter, Sphingobacterium, and Serratia were the dominant bacterial genera in the sclerotia. Pseudomonas and Pedobacter are heterotrophic, Sphingobacterium decomposes urea, and Serratia reduce nitrate. Two strains of bacteria, $\mathrm{N}-2$ and $\mathrm{N}-26$, were isolated from the sclerotia of the $C$. militaris, cultured, biochemically characterized, and identified as Stenotrophomonas maltophilia and Pseudomonas baetica, respectively. When these isolated strains were respectively cocultured with $C$. militaris, the mycelium biomass, mycelium pellet diameter, and cordycepin content decreased.

\section{Conclusions}

Bacteria in sclerotia have an important effect on the growth of $C$. militaris and the production of its metabolites.

\section{Background}

Cordyceps militaris is a member of the fungal genus Cordyceps and is a traditional Chinese medicine, containing a variety of active substances including cordycepin (3'-deoxyadenosine), cordyceps polysaccharide, and cordyceps acid [1]. In humans, cordycepin and cordyceps polysaccharide improve immunity; protect the kidney; have antifatigue and antioxidation properties; inhibit bacterial growth, inflammation, and tumors; and can be used as an effective anticancer supplement [2]. Cordycepin has the potential to be used against COVID-19 [3]. Much attention has been paid to the development of $C$. militaris $[4,5]$.

C. militaris parasitizes insect larvae [6]. It is distributed throughout the Northern Hemisphere [7]. Its host insects include Lepidoptera, Coleoptera, Diptera, and Hymenoptera [8]. Because the host insects contain a variety of microorganisms, the sclerotia of Cordyceps also contain various microorganisms [9]. In sclerotia of $C$. militaris collected in Yunnan Province, China, the bacteria identified included members of the phyla Proteobacteria, Acidobacteria, Bacteroidetes, and Actinobacteria, and the genera Pedobacter, 
Phyllobacterium, Pseudomonas, Mesorhizobium, Bradyrhizobium, Variovorax, Sphingomonas, and others [10]. The bacteria in sclerotia of $C$. sinensis were dominated by Proteobacteria and Actinobacteria and included Pseudomonas, Rhodoferax, Pedobacter, and Sphingomonas $[11,12]$. In the sclerotia of $C$. cicadae, Proteobacteria, Bacteroidetes, and Actinobacteria were the main bacterial groups, and Pseudomonas and Serratia were dominant genera [13].

Some of these symbiotic/associated microorganisms have the ability to regulate the growth characteristics and metabolites of Cordyceps. Herbaspirillum and Phyllobacterium on the fruiting body can increase the bioactive compound content of $C$. militaris [10]. Three species of bacteria (Serratia marcescens, Cedecea neteri and Enterobacter aerogenes) isolated from C. cicadae promoted the production of N6-(2-hydroxyethyl) adenosine and decreased the production of adenosine, uridine and guanosine [14]. In co-culture, the color of the fungus and the morphology of its mycelia may change [15, 16]. The effect of microorganisms on the sclerotia of $C$. militaris needs further research.

In this study, the microbial composition in the sclerotia of wild C. militaris from Liaoning Province, China, was analyzed using high-throughput sequencing technology, and two strains of bacteria were isolated, characterized, and identified. Then, these strains were co-cultured with $C$. militaris to explore the effects on mycelium pellet morphology, biomass of mycelium pellets, and production of cordycepin and polysaccharides.

\section{Results And Analysis}

\section{Bacterial community composition and ecological function}

A total of 204,067 effective sequences were detected in three samples of $C$. militaris collected in October 2019 in Liaoning Province, China; 62,929-71,212 sequences were obtained for each sample, with average length $423.45-425.61 \mathrm{bp}$. With the increase of the number of sample sequences, the ShannonWinner index curve flattened out (Additional file 1: Table S1), indicating that the sequencing data depth in this experiment comprehensively reflected the bacterial community in the samples.

Bacteria identified in the sclerotia included 21 phyla, 46 classes, 123 orders, 195 families, 321 genera, 450 species, and 549 operational taxonomic units (OTUs). At the phylum level (Fig. 1), Proteobacteria (average relative abundance of OTU 68\%), Bacteroidetes (24\%), and Actinobacteria (8\%) were dominant. At the genus level, Pseudomonas (17\%), Unclassified Enterobacteriaceae (14\%), Pedobacter (11\%), Sphingobacterium (11\%), Serratia (10\%), Rhodococcus (6\%), and Acromobacter (6\%) were dominant.

Forty-two OTUs were common to the three samples (Additional file 2: Fig. S2), accounting for only $7.65 \%$ of the total number of OTUs. These 42 OTUs were uploaded to the FAPROTAX system [17] for analysis, and predicted functions of 17 genera represented by 21 OTUs were identified (Fig. 2; Additional file 5: Table S1). Stenotrophomonas (OTU1490) is animal parasitic or symbiotic, and is a human pathogen. It actively participates in the nitrogen cycle. Sphingobacterium (OTU2342) is involved in urea 
decomposition. Pseudomonas (OTU1448, OTU2330, and OTU2314) is chemoheterotrophic. Rhodococcus (OTU1539 and OTU1423) degrades aromatic hydrocarbons and aliphatic non-paraffin hydrocarbons.

\section{Isolation and identification of bacteria}

Two pure strains of bacteria, $\mathrm{N}-2$ and $\mathrm{N}-26$, were isolated from sclerotia of $C$. militaris. Strain $\mathrm{N}-2$ is short rod-shaped (7.2-9.4 × 3.2-3.8 $\mu \mathrm{m}$ ) (Fig. 3) and Gram-negative; colonies were slightly convex, pale yellow, smooth, moist, and opaque. Physiological and biochemical tests (Additional file 6: Table S2) showed that strain $\mathrm{N}-2$ has swimming ability, can decompose glucose to produce pyruvate, and can decarboxylate the pyruvate and convert it into alcohol and other substances. In addition, ornithine decarboxylase, lysine decarboxylase and amino acid decarboxylase were detected, indicating that strain $\mathrm{N}-2$ can decarboxylate amino acids $(-\mathrm{COOH})$ to produce an amine and $\mathrm{CO}_{2}$. Strain $\mathrm{N}-2$ cannot use mannitol, inositol, sorbitol, melibiose, ribitol, raffinose, xylose, or maltose as carbon sources. Using the methods described in the eighth edition of "Bergey's Manual of Systematic Bacteriology", strain N-2 was identified as belonging to the genus Stenotrophomonas [18]. By Basic Local Alignment Search Tool (BLAST) analysis, the 16S rRNA gene sequence of strain $\mathrm{N}-2$ was found to be $99.93 \%$ identical to that of S. maltophilia GZUIFR-YC01. Strain N-2 was identified as S. maltophilia (Hugh) (Additional file 4: Fig. S4) (NCBI accession number: MW829549).

Strain N-26 is short rod-shaped $(9.5-11.5 \times 4.2-5 \mu \mathrm{m})$, Gram-negative, and its colonies are yellow, smooth, moist and opaque, with a central bulge. The semi-solid agar (dynamic test) of strain N-26 was positive, the Voges-Proskauer test was positive, and the Methyl Red test was negative. The strain was positive for ornithine decarboxylase, lysine decarboxylase and amino acid decarboxylase. The strain could not use mannitol, inositol, sorbitol, melibiose alcohol, raffinose, xylose, or maltose as carbon sources. In BLAST analysis, the 16S rRNA gene sequence of strain N-26 was $99.71 \%$ identical to that of Pseudomonas baetica YHNG5 (Additional file 4: Fig. S4), which led to the identification of strain N-26 as P. baetica (Lopez) (NCBI Accession number: MW829550).

\section{Interaction between isolated bacteria and $C$. militaris}

On potato-dextrose-agar (PDA) plates, S. maltophilia N-2 had an inhibitory effect on the growth of mycelium of $C$. militaris. Strain N2 released something that slowed the growth of $C$. militaris mycelia near the area of S. maltophilia N-2 growth (Fig. 4a). P. baetica N-26 did not inhibit mycelial growth on PDA plates (Fig. 4b).

The dry weight of mycelium pellets decreased from $1.57 \mathrm{~g} /$ flask in the control to $0.21 \mathrm{~g} /$ flask in the presence of $S$. maltophilia strain $\mathrm{N}-2$ or $0.35 \mathrm{~g} /$ flask in the presence of $P$. baetica strain $\mathrm{N}-26$ strain after co-culture with $C$. militaris for 7 days; these differences were highly significant when compared with the control $(P<0.01)$ (Fig. 5a). The diameter of mycelium pellets decreased from $7.38 \mathrm{~mm}$ in the control to 3.29 and $3.63 \mathrm{~mm}$ after culture in the presence of strains $\mathrm{N}-2$ and $\mathrm{N}-26$, respectively $(\mathrm{P}<0.01)$ (Fig. $5 \mathrm{~b})$. The addition of bacteria decreased the cordycepin content of the culture medium from $44.04 \mu \mathrm{g} / \mathrm{mL}$ in the control to $6.55 \mu \mathrm{g} / \mathrm{mL}$ with strain $\mathrm{N}-2$ or $2.69 \mu \mathrm{g} / \mathrm{mL}$ with strain $\mathrm{N}-26(\mathrm{P}<0.01)$ (Fig. 5c). The content 
of extracellular polysaccharide (EPS) was decreased $(5.08 \mathrm{mg} / \mathrm{mL})$ after $\mathrm{N}-2$ supplementation, and the difference was significant compared with the control $(6.75 \mathrm{mg} / \mathrm{mL})(P<0.05)$, while the addition of strain $\mathrm{N}-26$ increased the amount of EPS $(7.38 \mathrm{mg} / \mathrm{mL})$ (Fig. $5 \mathrm{~d})$.

\section{Discussion}

The bacteria present in sclerotia of $C$. militaris sampled from Liaoning Province, China, were identified using high-throughput sequencing technology. Pseudomonas were more abundant in sclerotia of $C$. militaris isolated in Liaoning Province than in C. militaris isolated in Yunnan Province, while Phyllobacterium, Mesorhizobium, and Bradyrhizobium were less abundant in the former [10]. The relative abundance of Mesorhizobium, Bradyrhizobium, Sphingomonas, and Labrys in sclerotia samples from Liaoning Province was lower than in samples from Yunnan Province (Table 1). Pseudomonas, Pedobacter, Phyllobacterium, Mesorhizobium, Bradyrhizobium, Sphingomonas, Variovorax, and Labrys were found in $C$. militaris samples from both Yunnan Province (southwest China, $25.40 \mathrm{~N}, 102.92 \mathrm{~W}$ ) and Liaoning Province (northeast China, 42.39 N, 124.26 E), but their relative abundances were different, which may be related to differences of the insect host and environmental conditions [19]. These same bacteria found in sclerotia of $C$. militaris from different geographical locations may be the key microorganism in the microenvironment of $C$. militaris and perform important functions [20]. Functional prediction (Table 1) showed that Pseudomonas, Pedobacter, Labrys, and Sphingomonas are chemoheterotrophic, while Stenotrophomonas functions in the nitrogen cycle. Pseudomonas, Phyllobacterium, Mesorhizobium, Bradyrhizobium, Pedobacter, Variovorax, and Sphingomonas belong to the microbiome of the plant rhizosphere [21,22]. These microorganisms may help to maintain plant hormone balance, control root development, promote nutrient acquisition, and prevent disease, improving plant growth and maintaining plant health [23]. The microorganisms are also ingested by root-feeding insects When Cordyceps spp. invade insects, the microorganisms in the insect gut interact with the fungus.

Stenotrophomonas maltophilia, a parasitic bacterium of insects [24], can promote the digestion and absorption of food by the host by secreting enzymes such as cellulase, amylase, protease, and chitinase; these enzymes inhibit the integrity of fungal hyphae and biofilm formation [25-27]. In insects, $S$. maltophilia can inhibit the growth of Beauveria bassiana (a fungus that parasitizes arthropods) [28]. Therefore, S. maltophilia can play a protective role in an insect host. S. maltophilia participates in the sulfur and nitrogen cycles, degrades complex compounds and pollutants, and promotes plant growth and health [29]. We conclude that $S$. maltophilia plays an important ecological role in the sclerotia of $C$. militaris.

Pseudomonas has many functions, e.g., P. fluorescens secretes luciferin and inhibits the growth of Escherichia coli in insects [30], decomposes wood, synthesizes multiple vitamins, and suppresses fungi in beetles [31]. $P$. aeruginosa strain BGF-2 isolated from German cockroach could inhibit the growth of $B$. bassiana [32]. Pseudomonas has a flexible metabolism that allows it to synthesize a wide range of 
antibiotics to ward off competitors and protect itself from predators, and to produce chemical signaling molecules that sustain intraspecies and interspecies interactions [33].

The relative abundance of bacteria in insects may be related to growth stimulation by parasitic fungi. For example, the biomass of $P$. fragi (a bacterium found in Thitarodes and Hepialus ghost moths) increased after invasion by $C$. sinensis, and $P$. fragi became the dominant bacterium and participated in the process of larval mummification [34]. Both Stenotrophomonas and Pseudomonas have been reported to inhibit conidial germination and mycelial growth of $B$. bassiana [28]. The two bacterial strains tested in this study had a similar effect on the hyphae of $C$. militaris. These findings indicate that using parasitic bacteria to inhibit fungal invasion is a protection mechanism of insects.

In the present study, the biomass of $C$. militaris decreased after co-culture with strain $\mathrm{N}-2$ (S. maltophilia) or $\mathrm{N}-26$ (P. baetica), so the content of cordycepin in the culture medium decreased accordingly. Several mechanisms could explain this effect. One is inhibition of the expression of cordycepin-synthesis-related genes (cns1, cns2, cns3, and cns4) [35]; this can be verified by quantitative PCR in later study.

Alternatively, (a) key enzyme(s) involved in cordycepin synthesis may have been inhibited. It is also possible that the mycelium structure was damaged in the co-culture process, which could be observed by using cryo-electron microscopy after co-culture. Or, cordycepin may be produced at around the usual level but used by the co-cultured bacterium. Why the polysaccharide content in cultures treated with strain N26 was higher than that in the control group also requires further study.

Because cordycepin has antibacterial function [36], we speculate that its ecological role is to inhibit the growth of some bacteria, to create good conditions for $C$. militaris and keep the insect host from decaying. Our data indicate that some symbiotic bacteria may inhibit the production of cordycepin. We speculate that other symbiotic bacteria may promote the production of cordycepin. Thus, we aim to isolate other microorganisms from the sclerotia and further explore the relationships between the isolates and $C$. militaris. When more and more interactions are revealed, the ecological functions of microbes in the sclerotia will become clear.

\section{Conclusions}

There are diverse bacteria in the sclerotia of $C$. militaris, among which Pseudomonas, Pedobacter, and Serratia are the dominant genera. This study reveals the interactions between $C$. militaris and isolated strains of Stenotrophomonas maltophilia and Pseudomonas baetica; these bacteria had inhibitory effects on the biomass, mycelial pellet diameter, and cordycepin yield of $C$. militaris.

\section{Materials And Methods}

\section{Sample source and treatment}

Samples: C. militaris was collected in October 2019 from Tieling City, Liaoning Province, China, (42.39 N, 124.26 E), $240 \mathrm{~m}$ above sea level, in a broad-leaved mixed forest. The strain C. militaris (L.) Link was 
stored in the Institute of Fungi Resources of Guizhou University (GZUIFR), strain number SYCM1910.

The 12 C. militaris obtained from Liaoning Province were divided into three samples for analysis in this work. In other words, each sample was a mixed sample.

Sclerotia sample preparation followed the method of Zeng [37] with slight modifications. C. militaris was rinsed with sterile water to remove residual soil on the insect surface, soaked alternatively with $75 \%$ alcohol and $2 \%$ sodium hypochlorite three times for 20 s each time, and then rinsed with sterile water. After removal of the body wall of the insect, the specimen was sclerotia. Each sclerotia sample of C.militaris weighed about $3.5 \mathrm{~g}$. The samples were stored at $-80^{\circ} \mathrm{C}$ until analysis.

\section{Culture media and isolation of bacterial strains}

LB medium contained tryptone $10 \mathrm{~g} / \mathrm{L}$, yeast extract $5 \mathrm{~g} / \mathrm{L}, \mathrm{NaCl} 10 \mathrm{~g} / \mathrm{L}$, and agar $15 \mathrm{~g} / \mathrm{L}(\mathrm{pH} \approx 7.0)$. Potato-dextrose-agar contained potato $200 \mathrm{~g} / \mathrm{L}$, glucose $20 \mathrm{~g} / \mathrm{L}$, and agar $15 \mathrm{~g} / \mathrm{L}(\mathrm{pH} \approx 7.0)$. Sabouraud's medium contained glucose $40 \mathrm{~g} / \mathrm{L}$ and peptone $10 \mathrm{~g} / \mathrm{L}(\mathrm{pH} \approx 7.0)$.

C. militaris sclerotia sample $(0.5 \mathrm{~g})$ was ground and its suspension was placed on LB-agar for microbial isolation.

\section{Total bacterial DNA extraction, PCR amplification, and high-throughput sequencing}

C. militaris sclerotia samples ( $3.0 \mathrm{~g}$ ) were taken, ground in liquid nitrogen, and total microbial DNA was extracted according to the instructions of the E.Z.N.A. ${ }^{\circledR}$ SOIL DNA Kit (Omega, USA). PCR amplification used TransStart FastPFU DNA Polymerase. The reaction system contained: $5 \times$ FastPFU buffer $(4 \mu \mathrm{L}), 2.5$ $\mathrm{mmol} / \mathrm{L}$ dNTPs $(2 \mu \mathrm{L}), 5 \mu \mathrm{mol} / \mathrm{L}$ primers 338F (5'-ACTCCTACGGGAGCAG-3') and 806R (5'-

GGACTACHVGGGTWTCTA-3') (0.8 $\mu \mathrm{L}$ each) targeting the V3-V4 region of $16 \mathrm{~S}$ rRNA genes [38], FastPFU Polymerase $(0.4 \mu \mathrm{L})$, bovine serum albumin $(0.2 \mu \mathrm{L}, 1 \mu \mathrm{g} / \mu \mathrm{L})$, and template DNA (10 ng), supplemented with $\mathrm{ddH}_{2} \mathrm{O}$ to $20 \mu \mathrm{L}$. Reaction used an $\mathrm{ABI}$ Gene AMP® 9700 PCR instrument. The reaction parameters were $95^{\circ} \mathrm{C}$ for $3 \mathrm{~min} ; 30$ cycles of $95^{\circ} \mathrm{C}$ for $30 \mathrm{~s}, 55^{\circ} \mathrm{C}$ for $30 \mathrm{~s}$, and $72{ }^{\circ} \mathrm{C}$ for $45 \mathrm{~s}$; and a final extension at $72{ }^{\circ} \mathrm{C}$ for $10 \mathrm{~min}$. The amplified products were sent to Shanghai Major Biomedical Technology Co., Ltd. and sequenced using the lllumina MiSeq platform.

\section{Identification of bacteria isolated from sclerotia}

Isolated bacteria were observed by scanning electron microscopy (SU8100, HITACHI), and their physiological and biochemical characteristics were identified using bacterial biochemical identification strips HBIG05 and HBIG08 (Qingdao Hopebio Biotechnology Co., Ltd.). Bacterial DNA was extracted according to the procedures for the Bacterial Genomic DNA Extraction Kit DP2002 (Beijing Bioteke Biotechnology Co., Ltd.). The 16S rRNA gene was amplified in all DNA extracts using primers 27F (5'AGAGTTTGATCCTGGCTCAG-3') and 1492R (5'-GGTTACCTTGTTACGACTT-3') [39]. The reaction mixture ( $25 \mu \mathrm{L}$ in total) contained $1 \mu \mathrm{mol} / \mathrm{L}$ primers ( $1 \mu \mathrm{L}$ each), $10 \mathrm{ng} / \mu \mathrm{L}$ DNA template $(2 \mu \mathrm{L})$, Master Mix (green) (including DNA polymerase, buffer, and dNTPs;12.5 $\mu \mathrm{L}$, product number TSE005, Tsingke 
Biotechnology Co., Ltd.) and $\mathrm{ddH}_{2} \mathrm{O}(8.5 \mu \mathrm{L})$. The PCR conditions were: predenaturation at $95^{\circ} \mathrm{C}$ for 3 min; 32 cycles of denaturation at $94^{\circ} \mathrm{C}$ for $30 \mathrm{~s}$, annealing at $55^{\circ} \mathrm{C}$ for $30 \mathrm{~s}$, and extension at $72{ }^{\circ} \mathrm{C}$ for 30 $\mathrm{s}$; and a final extension at $72^{\circ} \mathrm{C}$ for $10 \mathrm{~min}$. PCR products were sequenced by Tsingke Biotechnology Co., Ltd. Using the sequence data, BLAST was performed against DNA sequences in GenBank, and the sequences of related species (similarity $>97 \%$ ) were downloaded. Using Pseudomonas carboxydohydrogena as the outgroup, a phylogenetic tree was constructed by the neighbor-joining method using MEGA X software with 1000 bootstrap replicates.

\section{Functional analysis of bacteria isolated from sclerotia}

\section{Plate co-culture}

C. militaris SYCM1910 was inoculated in the center of a PDA plate and cultured at $25^{\circ} \mathrm{C}$ for 7 days. Then, bacteria were inoculated at three locations on the periphery of the colony $(25 \mathrm{~mm}$ from the point where $C$. militaris had been inoculated) and culture was continued at $25^{\circ} \mathrm{C}$ for 7 days.

\section{Coculture in liquid}

A piece of mycelium block of $C$. militaris cultured for 21 days was inoculated into a 250-mL triangular flask containing $100 \mathrm{~mL}$ Sabouraud's medium and cultured on a magnetic stirrer at $25^{\circ} \mathrm{C}$ for 3 days. Then, $1 \mathrm{~mL} /$ flask of bacterial suspension (bacterial cell density $1.5 \times 10^{8}$ colony-forming units $/ \mathrm{mL}$ ) was added and culture was continued at $120 \mathrm{r} / \mathrm{min}$ and $25^{\circ} \mathrm{C}$ for 7 days.

Measurement of physical indicators: Dry weight of mycelium pellets was determined after the fermentation broth was filtered using qualitative filter paper and the pellets were dried to constant weight at $60{ }^{\circ} \mathrm{C}$. Then, the mycelium pellet diameter was measured using vernier calipers.

Biochemical determination: Cordycepin was determined by high-performance liquid chromatography according to the Agricultural Industry Standard NY/T 2116-2012 of the People's Republic of China, using a Thermo Fisher Ultima 3000RS system and a $\mathrm{C}_{18}$ column with mobile phase acetonitrile : water (5:95 v:v) at flow rate $1.0 \mathrm{~mL} / \mathrm{min}$, column temperature $35^{\circ} \mathrm{C}$, detection wavelength $260 \mathrm{~nm}$, and sample volume $10 \mu \mathrm{L}$. EPS was determined by the anthrone sulfuric acid method [40].

\section{Data processing}

\section{Sequence processing and OTU annotation}

Paired-end reads obtained by MiSeq sequencing were first stitched according to overlap relationship, and sequence quality was controlled and filtered at the same time. Effective sequences were obtained by distinguishing samples according to barcode and primer sequences at both ends of the sequence, and sequence direction was corrected to obtain optimized sequences. Using UPARSE software (http://www.drive5.com/uparse/), repetitive sequence OTU clustering was carried out with a threshold of 
$97 \%$ similarity, chimeras were removed in the process of clustering, and the RDP database (http://rdp.cme.msu.edu/) was used for OTU annotation.

The raw sequence reads obtained in this study were deposited in the NCBI Sequence Read Archive database under accession number PRJNA722375.

\section{Prediction of bacterial function}

FAPROTAX (http://www.zoology.ubc.ca/louca/FAPROTAX/) is a tool that can predict ecological functions of bacterial and archaea taxa from 16S rRNA amplicon sequencing [17]. We used it to identify ecological functions of OTUs. An OTU abundance table and taxonomic annotation of OTUs were inputted in the corresponding option box, and the PLOT option was selected. Then, predicted function output was obtained as an Excel spreadsheet. A heatmap was generated using the online tool at the website www.ehbio.com/ImageGP/.

\section{Data analysis and presentation}

Statistical analysis of the experimental data was performed using SPSS software v.22.0. The least significant difference test was used for one-way analysis of variance.

\section{Abbreviations}

BLAST: Basic local alignment search tool; NCBI: National Center for Biotechnology Information; EPS: Extracellular polysaccharide; $\mathrm{ddH}_{2} \mathrm{O}$ : Double distilled water.

\section{Declarations}

\section{Authors' contributions}

Li Luo conducted the experiments and wrote the manuscript. Jia-Xi Zhou was in charge of the revision of the manuscript. Zhong-Shun Xu provided samples. Ying-Ming Gao prepared the figures. Xiao Zou was in charge of reviewing the manuscript and funding the experiments.

\section{Funding}

This study was funded by the Science and Technology Department of Guizhou Province (Qian Ke He Zhi Cheng [2019] 2405), Science and Technology Project of the Anshun Tobacco Company (Zhong Yan Qian $\mathrm{Ke}[2020] 7)$.

\section{Availability of data and materials}

All data generated or analyzed during this study are included in this published article and its Supplementary Information files. 


\section{Ethics approval and consent to participate}

Not applicable.

\section{Consent for publication}

Not applicable.

\section{Competing Interests}

The authors declare that they have no competing interests.

\section{Acknowledgment}

We thank Liwen Bianji, Edanz Group China (www.liwenbianji.cn/ac), for editing the English text of a draft of this manuscript.

\section{References}

1. Das Shonkor K, Masuda M, Sakurai A, Sakakibara M. Medicinal uses of the mushroom Cordyceps militaris: current state and prospects. Fitoterapia. 2010; 81:961-968.

2. Tuli Hardeep S, Sharma Anil K, Sandhu Sardul S, Kashyap D. Cordycepin: A bioactive metabolite with therapeutic potential. Life Sci. 2013; 93:863-869.

3. Verma Akalesh K. Cordycepin: a bioactive metabolite of Cordyceps militaris and polyadenylation inhibitor with therapeutic potential against COVID-19. J Biomol Struct Dyn. 2020; 3:1-8.

4. Jin Y, Meng X, Qiu ZD, Su YP, Yu P, Qu P. Anti-tumor and anti-metastatic roles of cordycepin, one bioactive compound of Cordyceps militaris. Saudi J Biol Sci. 2018; 25, 991-995.

5. Lee CT, Huang KS, Shaw JF, Chen JR, Kuo WS, Shen GX, et al. Trends in the immunomodulatory effects of Cordyceps militaris: total extracts, polysaccharides and cordycepin. Front Pharmacol. 2020; 11:575704.

6. Xue YF, Wu LL, Ding YL, Cui XM, Han ZZ, Xu H. A new nucleoside and two new pyrrole alkaloid derivatives from Cordyceps militaris. Nat Prod Res. 2018;34(3):1-10.

7. Zhang S., Zhang YJ., Shrestha B. Xu JP, Wang CS, Liu XZ. Ophiocordyceps sinensis and Cordyceps militaris: research advances, issues and perspectives. Mycosystema. 2013. 32(4):577-597.In Chinese.

8. Shrestha B, Zhang WM, Zhang YJ, Liu XZ. The medicinal fungus Cordyceps militaris: research and development. Mycol Prog. 2012;11(3):599-614.

9. Simon JC, Marchesi Julian R, Mougel C, Selosse MA. Host-microbiota interactions: from holobiont theory to analysis. Microbiome. 2019;7(1):5.

10. Zhang XM, Tang DX, li QQ, Wang YB, Xu ZH, Li WJ, et al. Complex microbial communities inhabiting natural Cordyceps militaris and the habitat soil and their predicted functions. Antonie van Leeuwenhoek. 2021;114(4):465-477. 
11. Xia F, Liu Y, Guo MY, Shen GR, Lin J, Zhou XW. Pyrosequencing analysis revealed complex endogenetic microorganism community from natural DongChong XiaCao and its microhabitat. BMC Microbiol. 2016;16:196.

12. Xia F, Zhou X, Liu Y, Li YL, Bai XH, Zhou XW. Composition and predictive functional analysis of bacterial communities inhabiting Chinese cordyceps insight into conserved core microbiome. BMC Microbiol. 2019;19(1):105.

13. Mou D, Zeng ZY, Zhong WL, Zhou JX, Qu JJ, Zou X. Bacterial community structure and function of Cordyceps cicadae microecosystem in Guiyang. Acta Microbiol Sinica. 2021;61(2):469-481.In Chinese.

14. Qu QS., Yang F, Zhao CY, Shi XY. Analysis of the bacteria community in wild cicadae and its influence on the production of HEA and nucleosides in Cordyceps cicadae. J Appl Microbiol. 2019;127:17591767.

15. Tauber JP, Schroeckh V, Shelest E, Brakhage AA, HoffmeisterD. Bacteria induce pigment formation in the basidiomycete Serpula lacrymans. Environ Microbiol. 2016;18(12):5218-5227.

16. Bor B, Cen LJ, Agnello M, Shi WY, He XS. Morphological and physiological changes induced by contact-dependent interaction between Candida albicans and Fusobacterium nucleatum. Sci Rep. 2016;6:27956..

17. Sansupa C, Mohamed WSF, Hossen S, Disayathanoowat T, Wubet T, Purahong W. Can We Use Functional Annotation of Prokaryotic Taxa (FAPROTAX) to Assign the Ecological Functions of Soil Bacteria?. Appl Sci, 2021;11(688):688.

18. Palleroni NJ, Bradbury JF. Stenotrophomonas, a New Bacterial Genus for Xanthomonas maltophilia (Hugh 1980) Swings et al. 1983. Int J Syst Bacteriol, 1993;43(3): 606-609.

19. Yun JH, Roh SW, Whon TW, Jung MJ, Kim MS, Park DS, et al. Insect gut bacterial diversity determined by environmental habitat, diet, developmental stage, and phylogeny of host. Appl Environ Microbiol. 2014;80(17): 5254-5264.

20. Lemanceau P, Blouin M, Muller D, Moënne-Loccoz Y. Let the Core Microbiota Be Functional. Trends Plant Sci. 2017;22(7):583-595.

21. Etesami H, Glick BR. Halotolerant plant growth-promoting bacteria: Prospects for alleviating salinity stress in plants. Environ Exp Bot, 2020.178:104124.

1. Yin C, Vargas JMC, Schlatter DC, Hagerty CH, Hulbert SH, Paulitz TC. Rhizosphere community selection reveals bacteria associated with reduced root disease. Microbiome.2020; 9:86.

2. Xu J, Zhang YZ, Zhang PF, Trivedi P, Riera N, Wang YY, et al. The structure and function of the global citrus rhizosphere microbiome. Nat Commun. 2018;9(1):4984.

3. Gandotra S, Kumar A, Naga K, Bhuyan PM, Gogoi DK, Sharma K, et al. Bacterial community structure and diversity in the gut of muga silkworm, Antheraea assamensis (lepidoptera: saturniidae) from India. Insect Mol Biol. 2018;27(5):603-619. 
4. Ali Huda RK, Hemeda NF, Abdelaliem YF. Symbiotic cellulolytic bacteria from the gut of the subterranean termite psammotermes hypostoma desneux and their role in cellulose digestion. AMB Express. 2019; 9:111-120.

5. Jankiewicz U, Brzezinska MS. Purification, characterization, and gene cloning of a chitinase from Stenotrophomonas maltophilia N4. J Basic Microb. 2015;55(7):929-929.

6. Rossi BP, García C, Alcaraz E, Franco M. Stenotrophomonas maltophilia interferes via the DSFmediated quorum sensing system with Candida albicans filamentation and its planktonic and biofilm modes of growth. Revista Argentina De Microbiología. 2014;46(4):288-297.

7. Zhou FY, Wu XQ, Xu LT, Guo SH, Chen GH, Zhang XJ. Repressed Beauveria bassiana infections in Delia antiqua due to associated microbiota. Pest Manag Sci. 2018;75(1):170-179.

8. An SQ, Berg G. Stenotrophomonas maltophilia. Trends Microbiol. 2018;26(7): 637-638.

9. Roberts DC, Fleischer SJ, Sakamoto JM, Rasgon JL. Potential biological control of Erwinia tracheiphila by internal alimentary canal interactions in Acalymma vittatum with Pseudomonas fluorescens. J Appl Microbiol. 2018;125(4):1137-1146.

10. Peral-Aranega E, Saati-Santamaría Z, Kola rik M, Rivas R, García-Fraile P. Bacteria belonging to Pseudomonas typographisp. nov. from the Bark beetle Ips typographus Have Genomic Potential to Aid in the Host Ecology. Insects. 2020;11: 593.

11. Huang YH, Wang XJ, Zhang F, Huo XB, Fu RS, Liu JJ, et al. The identification of a bacterial strain BGI1 isolated from the intestinal flora of Blattella germanica, and its anti-entomopathogenic fungi activity. J Econ Entomol. 2013;1:43-49.

12. G"otze S, Stallforth P. Structure, properties, and biological functions of nonribosomal lipopeptides from Pseudomonads. Nat Prod Rep. 2019;37(1):29-54.

13. Wu H, Rao ZC, Cao L, Clercq PD, Han RC. Infection of Ophiocordyceps sinensis fungus causes dramatic changes in the microbiota of its Thitarodes host. Front Microbiol. 2020;11:577268.

14. Zheng P, Xia YL, Xiao GH, Xiong CH, Hu X, Zhang SW, et al. Genome sequence of the insect pathogenic fungus Cordyceps militaris, a valued traditional Chinese medicine. Genome Biol. 2011;12(11), R116.

15. Jiang Q, Lou ZX, Wang HX, Chen C. Antimicrobial effect and proposed action mechanism of cordycepin against Escherichia coli and Bacillus subtilis. J Microbiol. 2019;57(4): 288-297.

16. Zeng ZY, Xu ZS, Mou D., Xu SH., et al. Analyses on the structure and ecological function of fungal community in sclerotia, external mycelial layer covering ossified cicada epidermis and habitat soil of Isaria cicadae. Mycosystema. 2019;38(10):1710-1723. In Chinese.

17. Zeng Q, An S. Identifying the Biogeographic Patterns of Rare and Abundant Bacterial Communities Using Different Primer Sets on the Loess Plateau. Microorganisms, 2021, 9(1):139.

18. Palkova L, Tomova A, Repiska G, Babinska K, Bokor B, Mikula I, et al. Evaluation of 16S rRNA primer sets for characterisation of microbiota in paediatric patients with autism spectrum disorder. Sci Rep.2021;11(1): 6781. 
19. Guo M, Guo S, Yang H, Bu N, Dong C. Comparison of Major Bioactive Compounds of the Caterpillar Medicinal Mushroom, Cordyceps militaris (Ascomycetes), Fruiting Bodies Cultured on Wheat Substrate and Pupae. Int J Med Mushrooms, 2016, 18(4):327-336.

\section{Tables}

Table 1 Relative abundance and function prediction of bacterial composition in sclerotia of $C$. militaris isolates. 


\begin{tabular}{|c|c|c|c|}
\hline Genus & $\begin{array}{l}\text { C. militaris } \\
\text { from Yunnan }\end{array}$ & $\begin{array}{l}\text { C. } \\
\text { militaris } \\
\text { from } \\
\text { Liaoning }\end{array}$ & Predicted Function \\
\hline Pseudomonas & $2.01 \%-15.00 \%$ & $16.68 \%$ & 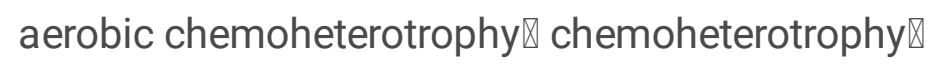 \\
\hline Pedobacter & $2.01 \%-15.00 \%$ & $10.81 \%$ & aerobic chemoheterotrophy $\llbracket$ chemoheterotrophy $\rrbracket$ \\
\hline Variovorax & $2.01 \%-15.00 \%$ & $3.14 \%$ & None \\
\hline Phyllobacterium & $2.01 \%-15.00 \%$ & $1.69 \%$ & None \\
\hline Labrys & $2.01 \%-15.00 \%$ & $0.98 \%$ & 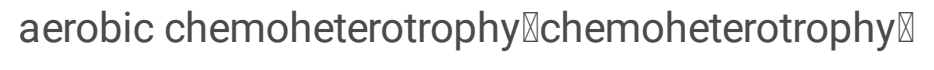 \\
\hline Mesorhizobium & $2.01 \%-15.00 \%$ & $0.05 \%$ & 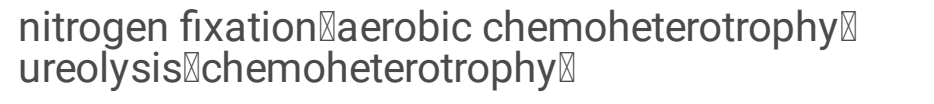 \\
\hline Sphingomonas & $2.01 \%-15.00 \%$ & $0.06 \%$ & 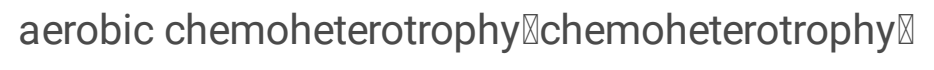 \\
\hline Bradyrhizobium & $2.01 \%-15.00 \%$ & $0.02 \%$ & None \\
\hline Serratia & -- & $9.65 \%$ & $\begin{array}{l}\text { fermentation } \bigotimes \text { nitrate reduction } \rrbracket \\
\text { chemoheterotrophy } ₫ \text { plant pathogen } \nabla\end{array}$ \\
\hline Achromobacter & -- & $6.26 \%$ & 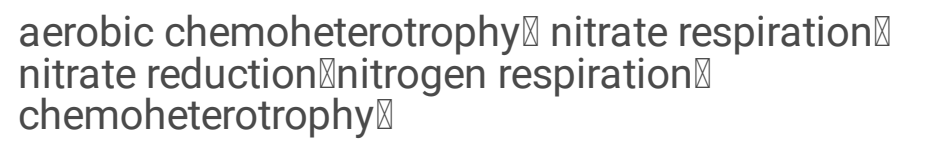 \\
\hline Rhodococcus & -- & $5.78 \%$ & 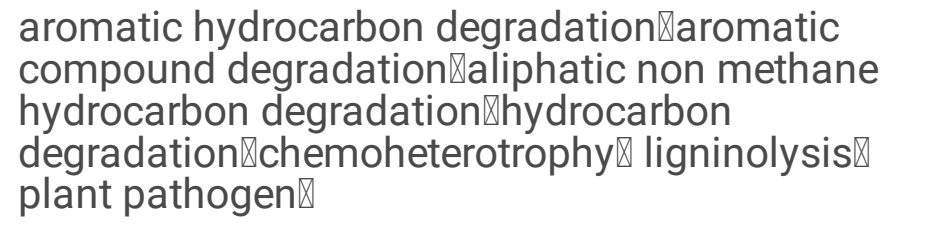 \\
\hline Pantoea & -- & $4.06 \%$ & 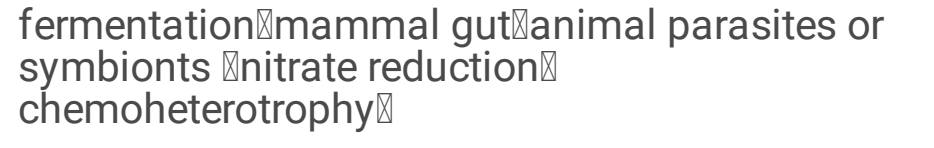 \\
\hline Luteibacter & -- & $3.89 \%$ & None \\
\hline Stenotrophomonas & -- & $1.82 \%$ & 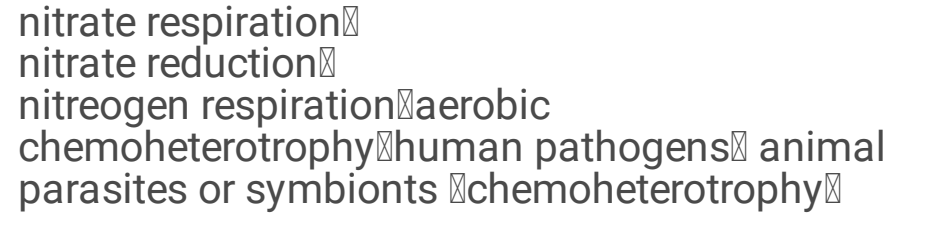 \\
\hline Ochrobactrum & -- & $1.02 \%$ & None \\
\hline
\end{tabular}

Note: "--" means not mentioned in the literature; "None" means that there was no result when a function was predicted using FAPROTAX.

\section{Figures}




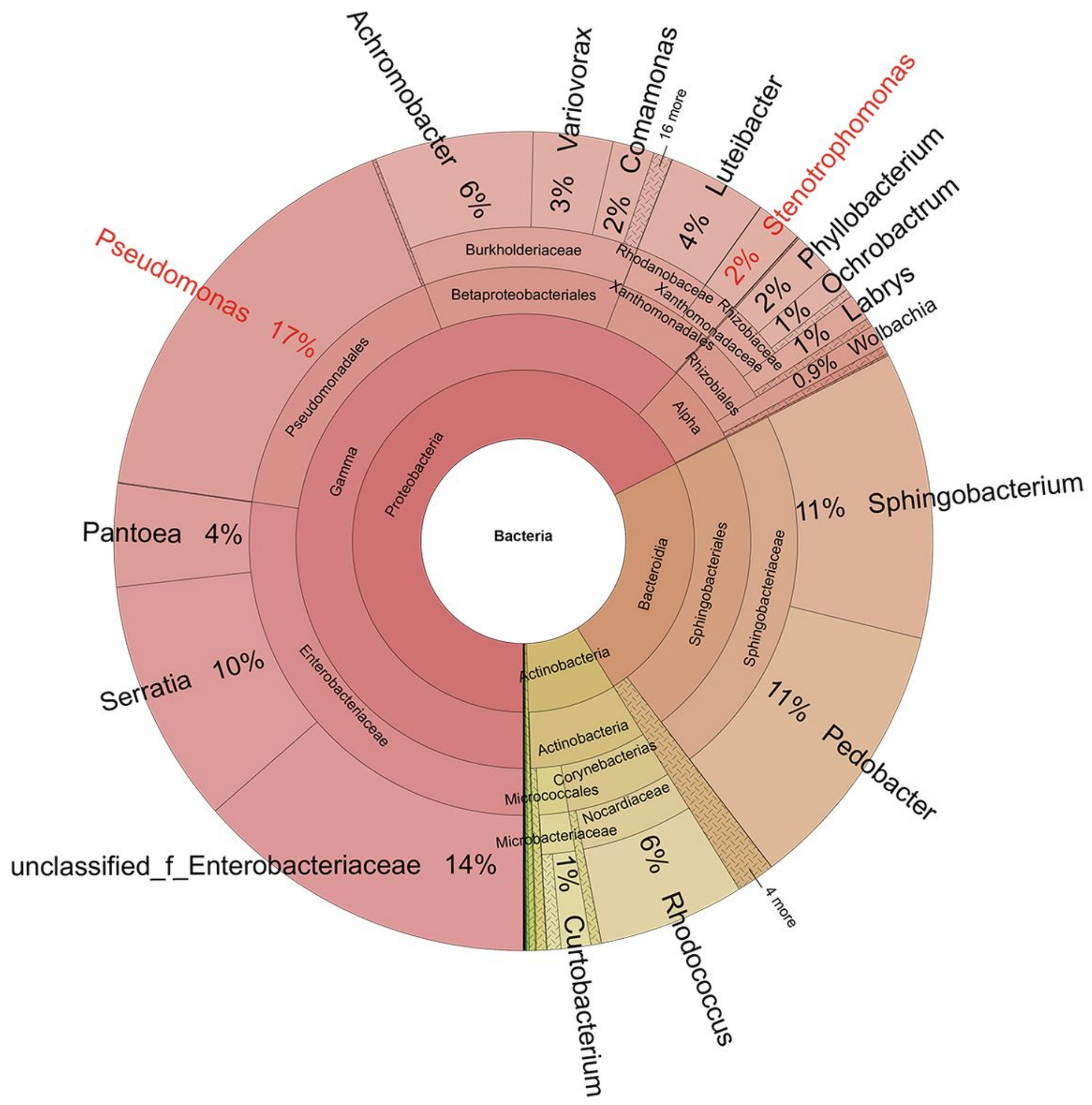

\section{Figure 1}

Taxonomic composition of the microbiome in sclerotia of Cordyceps militaris. Circles from inside to outside represent the community composition of the bacteria at different classification levels (kingdom, phylum, class, order, family, and genus, respectively). The size of the fan segments represents the relative proportion of the annotation results of different bacterial OTUs. 


\section{Main_Title}

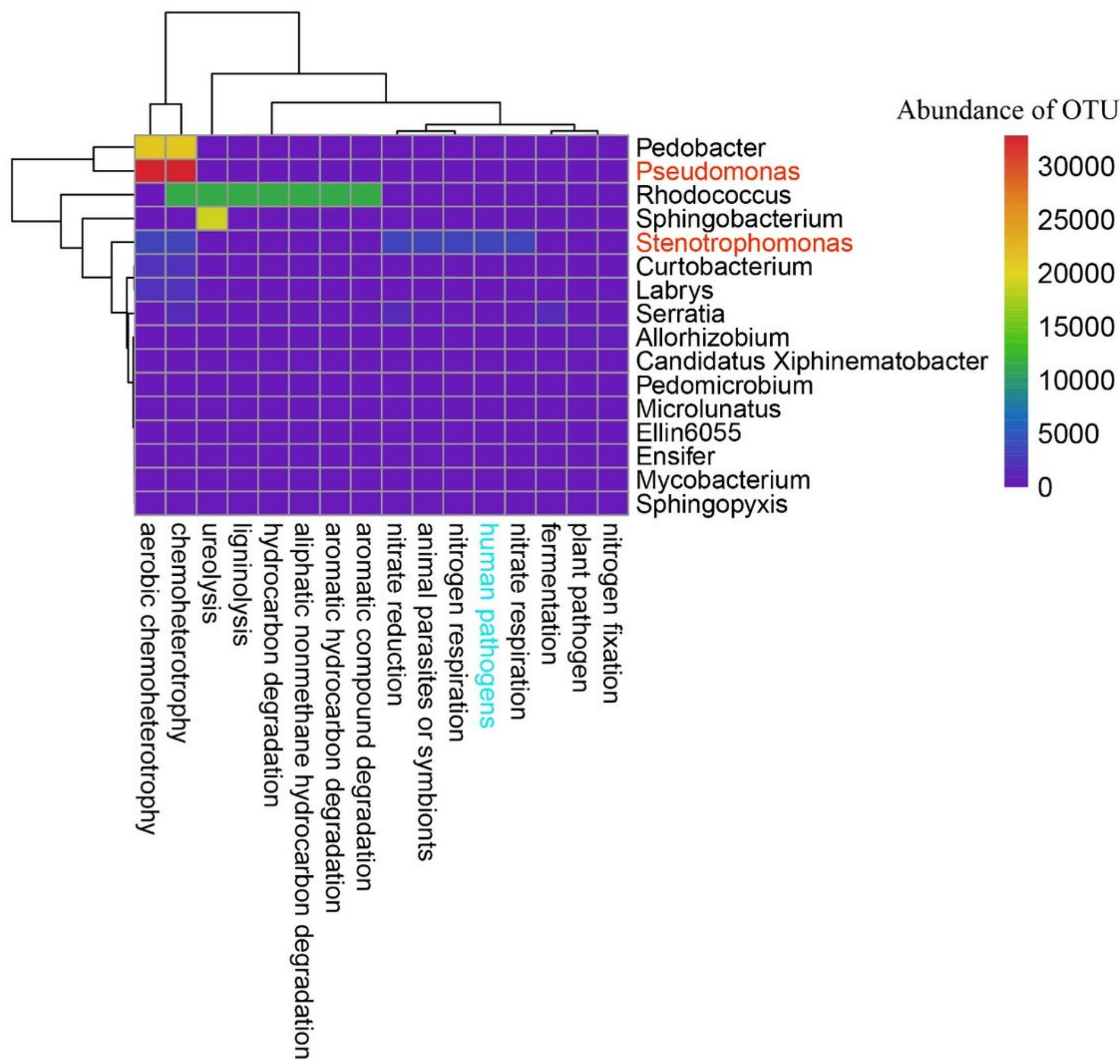

Figure 2

Functional prediction of the bacterial core microbiome in sclerotia of $\mathrm{C}$. militaris using FAPROTAX. Genera in red are the subject of this study. 


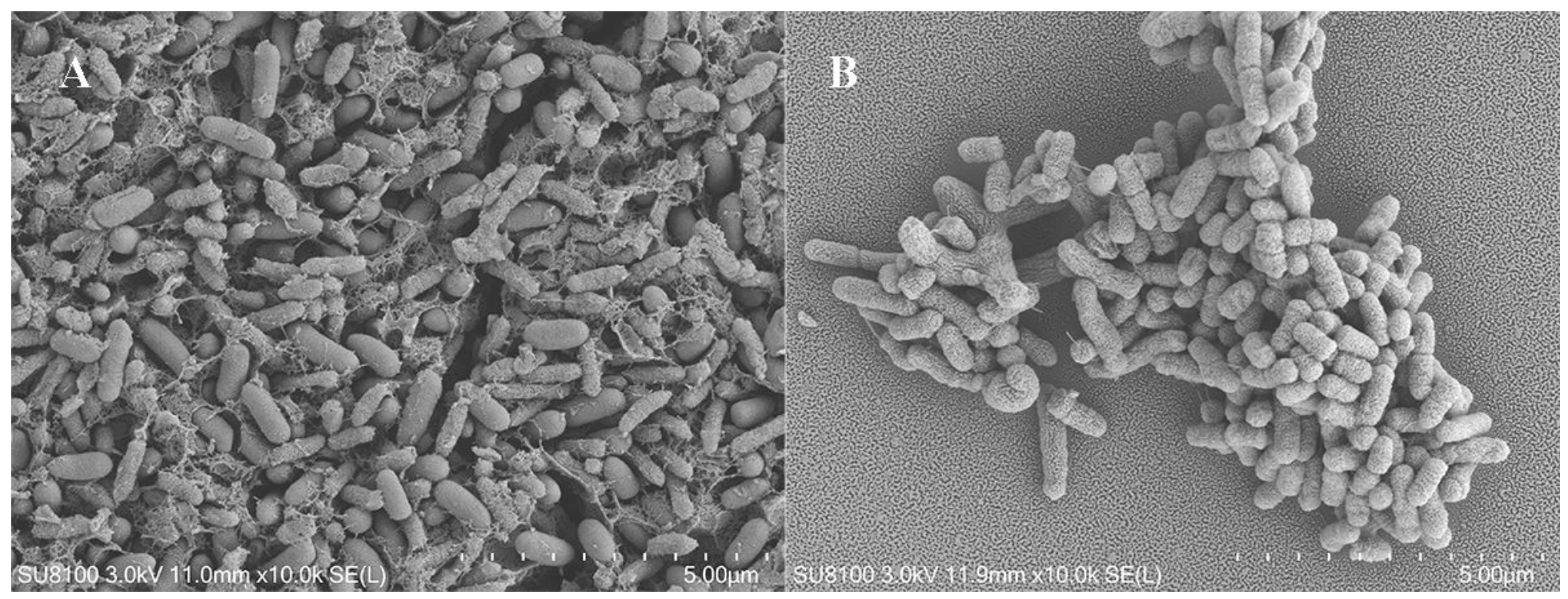

\section{Figure 3}

Scanning electron micrographs of strains a $\mathrm{N}-2$ and b N-26. Note: In Fig. 3a, the reticular-like structure on the surface of the bacteria is secretion by the bacteria. Note: In Fig.3a, the reticular structure on the surface of bacteria is the secretion of bacteria itself.

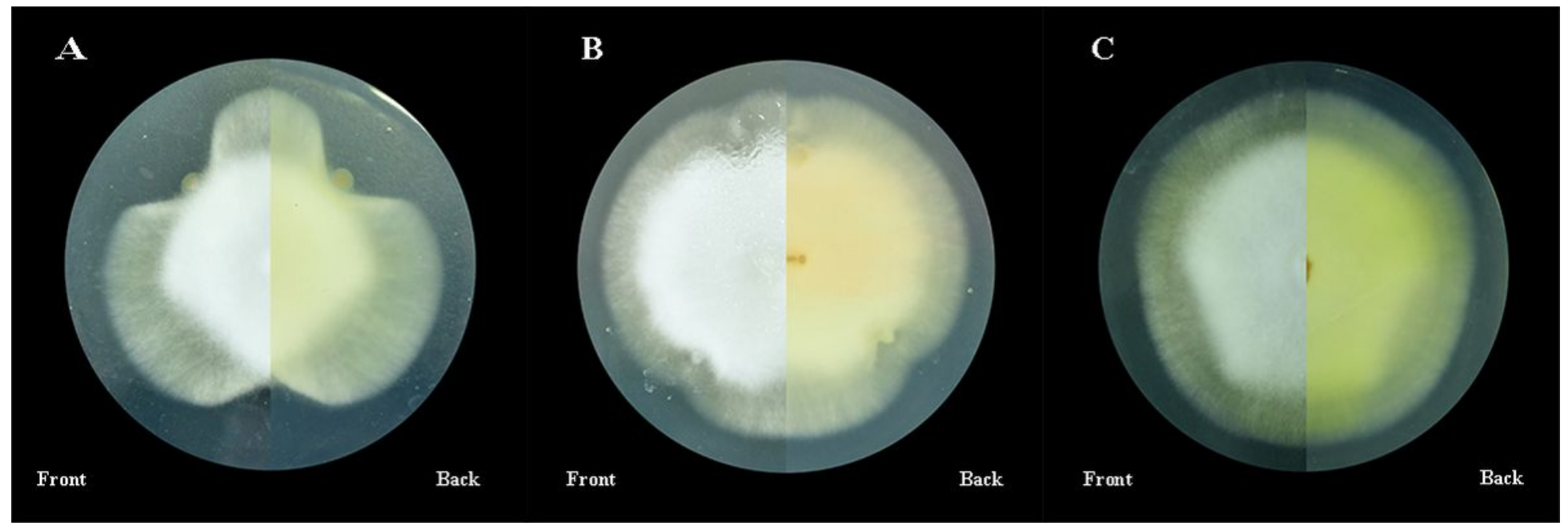

Figure 4

Co-culture on potato-dextrose-agar. a Strain N-2 and C. militaris, b strain N-26 and C. militaris, c C. militaris only. 

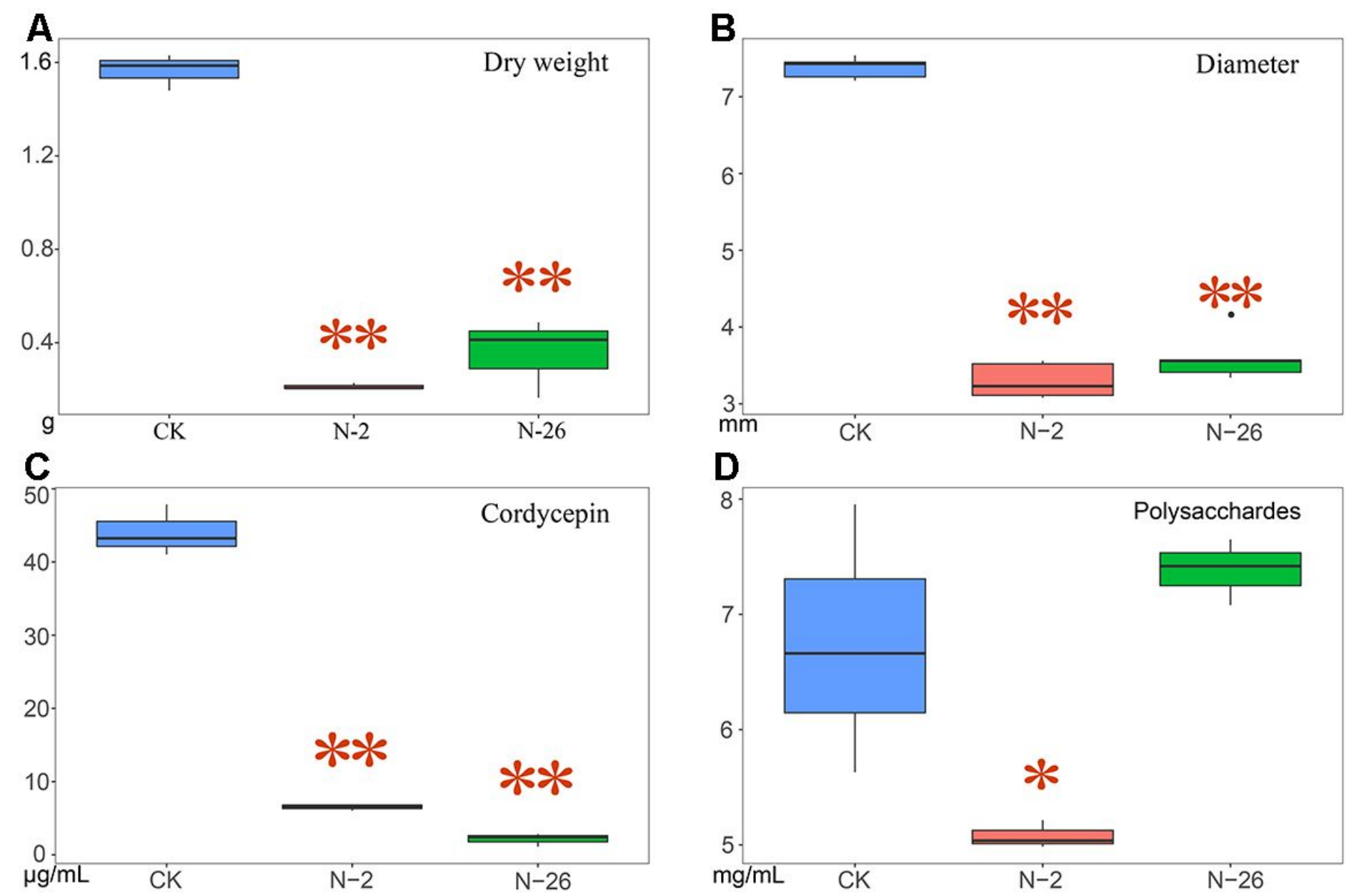

\section{Figure 5}

Effects of coculture of isolated bacterial strains with C. militaris. a Dry weight of mycelium pellets. $b$ Diameter of mycelium pellets. c Cordycepin concentration in medium. $d$ Polysaccharide concentration in medium. ${ }^{*} \mathrm{P}<0.05,{ }^{*} \mathrm{P}<0.01$.

\section{Supplementary Files}

This is a list of supplementary files associated with this preprint. Click to download.

- supplementary.docx 